\title{
Recent warming at Summit, Greenland: Global context and implications
}

\author{
Daniel McGrath, ${ }^{1}$ William Colgan, ${ }^{1,2}$ Nicolas Bayou, ${ }^{1}$ Atsuhiro Muto, ${ }^{3}$ \\ and Konrad Steffen ${ }^{4,5,6}$ \\ Received 28 January 2013; revised 31 March 2013; accepted 7 April 2013; published 20 May 2013.
}

[1] Observations at Summit, Greenland suggest that the annual mean near-surface air temperature increased at $0.09 \pm 0.01{ }^{\circ} \mathrm{C} / \mathrm{a}$ over the $1982-2011$ climatology period. This rate of warming, six times the global average, places Summit in the 99th percentile of all globally observed warming trends over this period. The rate of warming at Summit is increasing over time. During the instrumental period (1987-2011), warming has been greatest in the winter season, although the implications of summer warming are more acute. The annual maximum elevation of the equilibrium line and dry snow line has risen at 44 and $35 \mathrm{~m} / \mathrm{a}$ over the past 15 and 18 years, respectively. Extrapolation of this observed trend now suggests, with $95 \%$ confidence intervals, that the dry snow facies of the Greenland Ice Sheet will inevitably transition to percolation facies. There is a $50 \%$ probability of this transition occurring by 2025. Citation: McGrath, D., W. Colgan, N. Bayou, A. Muto, and K. Steffen (2013), Recent warming at Summit, Greenland: Global context and implications, Geophys. Res. Lett., 40, 2091-2096, doi:10.1002/grl.50456.

\section{Introduction}

[2] The frequency with which air temperature and melt records are being established in Greenland is exceptional. Nine of the ten warmest years since 1961 have occurred since 2000, while the six warmest summers have occurred since 2003 [Hanna et al., 2012]. Surface melt extent has increased by $\sim 16,800 \mathrm{~km}^{2} / \mathrm{a}$ over the 1979 to 2011 period [Box et al., 2011]. Record or near record melt extents occurred in 2002, 2005, 2007, 2010, and 2011, leading up to the 2012 extreme event, when $98.6 \%$ of the Greenland Ice Sheet (GrIS) briefly experienced surface melt [Nghiem et al., 2012]. In conjunction with the dramatic and sustained loss of Arctic sea ice extent and thickness [Cavalieri and

Additional supporting information may be found in the online version of this article.

${ }^{1}$ Cooperative Institute for Research in Environmental Sciences, University of Colorado Boulder, Boulder, Colorado, USA.

${ }^{2}$ Geological Survey of Denmark and Greenland, Copenhagen, Denmark.

${ }^{3}$ Department of Geosciences and Earth and Environmental Systems Institute, The Pennsylvania State University, University Park, Pennsylvania, USA.

${ }^{4}$ Snow and Landscape Research, Swiss Federal Institute for Forest, Birmensdorf, Switzerland.

${ }^{5}$ Swiss Federal Institute of Technology, Zürich, Switzerland.

${ }^{6}$ École Polytechnique Federal de Lausanne, Lausanne, Switzerland.

Corresponding author: D. McGrath, Cooperative Institute for Research in Environmental Sciences, University of Colorado at Boulder, UCB 216, Boulder, CO 80309-0216, USA. (daniel.mcgrath@colorado.edu)

(C)2013. American Geophysical Union. All Rights Reserved. 0094-8276/13/10.1002/grl.50456
Parkinson, 2012], these observations stress that the Arctic climate is no longer in steady state, whereby climate oscillates around a mean and extreme events are relatively rare. Instead, the Arctic climate is presently in a highly transient state, whereby extreme events frequently exceed the climatological mean as climate variables trend in preferred directions.

[3] Surface air temperature and melt decrease with increasing elevation on the GrIS, giving rise to distinct ice and snow zones, which gradually transitions from the ice facies in the ablation area, at the lowest elevations, through the wet snow and percolation facies at mid-elevations, to the dry snow facies at the highest elevations, where no surface melt occurs [Benson, 1962; reprinted 1996]. Here, we show that the observed expansion of GrIS surface melt extent over the past three decades [e.g., Tedesco et al., 2011] has driven an upward migration of both the equilibrium line and dry snow line. The brief record surface melt in July 2012, which extended over the traditional dry snow facies, including Summit, was unprecedented during the satellite era [Nghiem et al., 2012]. Prior to this event, the most recent melt event at Summit occurred in 1889, which was one of only eight such events to have occurred in the past $\sim 1500$ years [Clausen et al., 1988; Meese et al., 1994]. Summit melt frequency has varied throughout the Holocene, ranging from once per $\sim 82$ years from 5500 to $8500 \mathrm{BP}$, to once per $\sim 250$ years from 1000 to 4000 BP [Alley and Anandakrishnan, 1995].

[4] Runoff presently accounts for $\sim 50 \%$ of the $\sim 250 \mathrm{Gt}$ annual mass loss observed from the GrIS [Rignot et al., 2008; 2011; van den Broeke et al., 2009]. Record negative annual mass balances in 2010 and 2012, of $-430 \mathrm{Gt}$ and $-574 \mathrm{Gt}$, respectively, coincided with record negative surface mass balances [Velicogna and Wahr, 2006, updated; Box et al., 2012a; Hanna et al., 2012; Tedesco et al., 2013]. Greenland's melt season has lengthened by $>10$ days per decade, especially at low elevations near the ice margin, where meltwater production is greatest [Tedesco et al., 2013]. While the recent expansion of high elevation melt extent is unlikely to have contributed to runoff [Harper et al., 2012], the presence or absence of dry, percolation and wet snow facies remain an important indicator of ice sheet health. The potential loss of the dry snow facies may be viewed as an important, albeit very early, milestone in the transition of a viable ice sheet, one maintained by some balance of accumulation and ablation, to an ice sheet that has ultimately been tipped into irreversible decline by the loss of its dry snow accumulation area.

[5] We seek to place the 2012 GrIS-wide melt event in the context of both regional and global climatology and consider the future evolution of Greenland's ice and snow facies. First, we present a compilation of all mean near-surface air 
temperature (NSAT) observations from the vicinity of Summit, Greenland, from meteorological stations, firn temperatures and reanalysis data, over the 1950-2011 period. This NSAT record allows us to characterize the magnitude of the recent warming at Summit, which we then compare to a global inventory of observed air temperature trends. Second, we use in situ observations to estimate the annual maximum elevation of the $0^{\circ} \mathrm{C}$ isotherm, which delineates the lower boundary of the dry snow facies (i.e., the dry snow line), and the equilibrium line altitude (ELA) along a transect west of Summit during the 1995-2012 period. Extrapolating the observed trends in both features allows us to assess the future distribution of ice and snow facies in Greenland, and specifically, constrain the timing of the disappearance of the dry snow facies.

\section{Methods}

[6] NSATs compiled from meteorological stations and firn temperatures within $250 \mathrm{~km}$ of Summit, Greenland (Table S1) were corrected to the latitude and altitude of Summit using previously published altitudinal and latitudinal lapse rates [Steffen and Box, 2001]. In order to ensure a common datum, the positional information accompanying each in situ measurement was used to interpolate elevation from the digital elevation model of Scambos and Haran [2002]. Higher temporal resolution (e.g., hourly) meteorological station observations were first aggregated into monthly and then annual mean values, in which all 12 months were of the standard calendar year and had, on average, 95\% data coverage. NSATs observed at Greenland Ice Sheet Project II (GISP2) and Greenland Climate Network (GC-Net; Steffen and Box, [2001]) meteorological stations are presented from 1987 to present as annual and standard 3 month seasonal mean values.

[7] Surface skin temperatures (and thus firn temperatures) are systematically lower than the NSAT at Summit due to a persistent negative surface energy balance, which causes a quasi-permanent temperature inversion. We account for this discrepancy by calculating the difference between coincident GC-Net mean annual NSAT and $10 \mathrm{~m}$ firn temperatures. We accordingly assess a correction factor of $+0.9^{\circ} \mathrm{C}$ to all firn temperatures when deriving equivalent NSATs, which is consistent with an average $+0.7^{\circ} \mathrm{C}$ offset reported by Cuffey and Paterson [2010]. From the coincident firn and air temperature comparison, we also assess a temporal lag of -0.6 years to firn temperatures when determining the year of equivalent NSATs. NSATs inferred from the majority of firn temperatures $(75 \%$ of observations) were interpolated at $10 \mathrm{~m}$ depth from firn temperature profiles. At a minority of sites, however, single depth firn temperature observations, at depths between 8 and $10 \mathrm{~m}$ $(5 \%)$ and 10 and $15 \mathrm{~m}(20 \%)$, were treated as equivalent to $10 \mathrm{~m}$ temperatures (Table $\mathrm{S} 1$ ).

[8] The NSAT at Summit derived by the Modern-Era Retrospective Analysis for Research and Applications model (MERRA; Rienecker et al., [2011]) over the 1979-2011 satellite observation period agrees well with all available NSAT meteorological observations $(\mathrm{r}=0.74, \mathrm{n}=27, \mathrm{p}<0.01$; Figure 1 inset). We therefore include NSATs derived from MERRA in our compilation of Summit NSATs. We compare the recent warming trend in NSAT observed at Summit to previously published global surface air temperature trends (Figure 2; http://data.giss.nasa.gov/gistemp). This analysis includes land surface trends from the Goddard Institute of
Space Studies analysis [Hansen et al., 2010] and sea surface temperature trends from the Hadley Center analysis [Reynolds et al., 2002].

[9] We determine the maximum elevation of the $0^{\circ} \mathrm{C}$ isotherm (hereafter $0^{\circ} \mathrm{C} \mathrm{IE}$ ) and annual ELA along the $70.66^{\circ} \mathrm{N}$ parallel in West Greenland, the mean latitude of GC-Net stations JAR 1 (932 m), Swiss Camp (SC; $1176 \mathrm{~m})$, Crawford Point (CP; $2022 \mathrm{~m})$, and Summit $(3208 \mathrm{~m})$, over the period 1995-2012. The $0^{\circ} \mathrm{C} \mathrm{IE}$ is interpolated from an ordinary least squares (OLS) regression of hourly mean NSATs along the transect, except in 2012, when we apply an atmospheric lapse rate of $7.1^{\circ} \mathrm{C} / \mathrm{km}$ to extrapolate the $0^{\circ} \mathrm{C} \mathrm{IE}$ above Summit [Steffen and Box, 2001]. In the spirit of Benson [1962], who characterized the dry snow line with a given isotherm, we take the $0^{\circ} \mathrm{C} \mathrm{IE}$ to be the maximum elevation of surface snow melt and thus delineates the dry snow facies. We explore a range of temporal averaging thresholds $(24,6$, and $1 \mathrm{~h}$ periods) for determining the isotherm associated with the dry snow line, but find that only the $1 \mathrm{~h}$ threshold captures the 2012 melting event at Summit (Figures S1). This characterization is consistent with remote sensing observations of melt extent using both passive microwave and scatterometer instruments, which are highly sensitive to snow wetness [Steffen et al., 1993; Nghiem et al., 2001]. As NSAT is only a proxy for the complete surface energy balance, this choice may be conservative. For example, a second, albeit much weaker, Summit melt event was observed on 29 July 2012 by scatterometer, when the Summit NSAT only surpassed $0^{\circ} \mathrm{C}$ for $1 \mathrm{~min}$ [Nghiem et al., 2012].

[10] The annual ELA is calculated for the 1997-2011 period (except 2007 when data are not available), by interpolating the elevation of net zero surface mass balance via an OLS regression of observed surface mass balances along the GC-Net transect. Annual net surface height loss at JAR 1 and SC, due to ice ablation, is converted to water equivalent (w.eq.) assuming the density of ice $\left(900 \mathrm{~kg} / \mathrm{m}^{3}\right)$. Net surface height gain at $\mathrm{CP}$, due to snow accumulation, is converted to w.eq. using a mean density of $350 \mathrm{~kg} / \mathrm{m}^{3}$ derived from in situ snow pits. Following Harper et al. [2012], we assume all meltwater produced at CP infiltrates and refreezes in situ, as sufficient firn capacity remains to suppress runoff. Thus, any surface lowering at CP is attributed to densification rather than mass loss. We convert ELA to distance from the coast using observed ice sheet geometry [Scambos and Haran, 2002]. We assess temporal trends in ELA and $0^{\circ} \mathrm{C}$ IE using $95 \%$ confidence intervals generated by simulating the observed data 10,000 times within the uncertainty of the observations and performing an OLS regression in each simulation (Table S2). This process is repeated, sequentially removing one annual observation during each simulation, to derive the final confidence intervals. We extrapolate the observed trends in the ELA and $0^{\circ} \mathrm{C}$ IE to examine the potential future distribution of GrIS snow facies (Figure 3).

\section{Results}

[11] Observed NSAT over the 1950-2011 period at Summit exhibits a significant warming trend of $0.02 \pm$ $0.01^{\circ} \mathrm{C} / \mathrm{a} \quad(\mathrm{r}=0.39, \mathrm{df}=106, \mathrm{p}<0.01 ;$ Figure 1$)$. The warming trend increases to $0.09 \pm 0.01^{\circ} \mathrm{C} / \mathrm{a}$ over the 1982-2011 climatology period $(\mathrm{r}=0.61, \mathrm{df}=74, \mathrm{p}<0.01)$ and further increases to $0.12 \pm 0.02^{\circ} \mathrm{C} / \mathrm{a}$ over the $1992-2011$ 


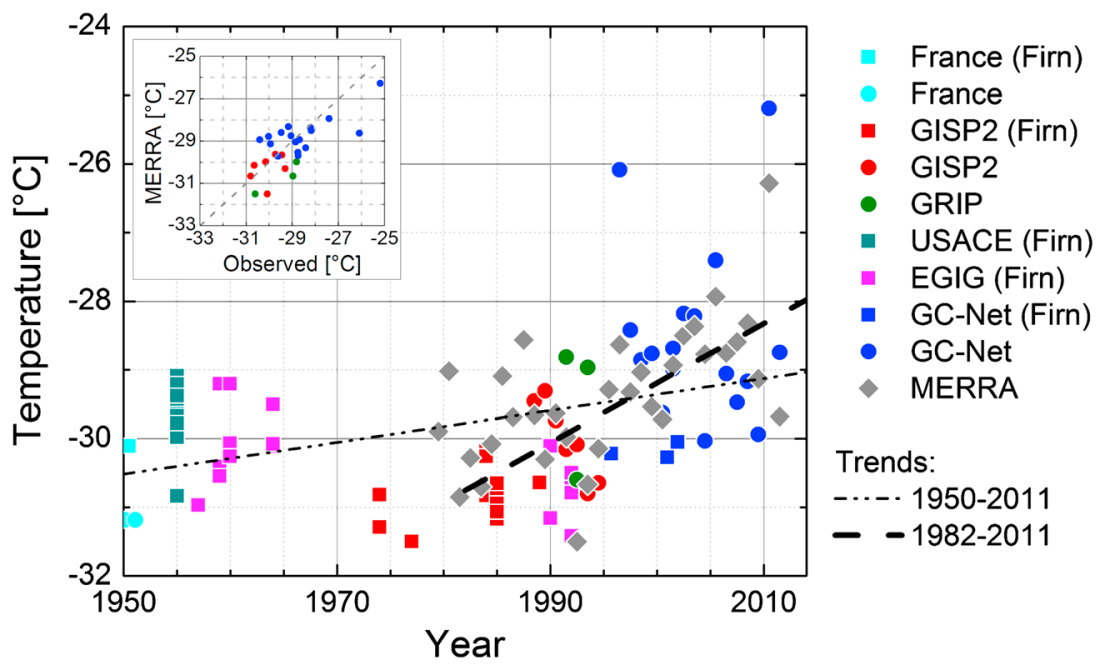

Figure 1. Observed mean annual near surface air temperature (NSAT) at Summit, Greenland between 1950 and 2011. Each data point represents one independent NSAT measurement. Circles denote meteorological station observations, squares denote firn temperature observations, and diamonds denote satellite-derived MERRA data. Observations are color-coded by collection agency and/or project (Table S1). There is a significant warming trend of $0.09 \pm 0.01^{\circ} \mathrm{C} / \mathrm{a}$ from 1982 to $2011(\mathrm{r}=0.61, \mathrm{df}=74, \mathrm{p}<0.01)$. Inset: Observed versus MERRA NSAT during the 1979-2011 period $(\mathrm{r}=0.74$, $\mathrm{n}=27, \mathrm{p}<0.01)$.

decade $(\mathrm{r}=0.58, \mathrm{df}=48, \mathrm{p}<0.01)$. The magnitude and spatial distribution of observed global surface temperature trends over the 30 year climatology period provides a global context for the recent warming experienced by Summit (Figure 2). The global area-averaged observed surface temperature trend over the 1982-2011 climatology period is $0.015^{\circ} \mathrm{C} / \mathrm{a}$, with a clear maximum exhibited over the Canadian Arctic. The observed $0.09^{\circ} \mathrm{C} / \mathrm{a}$ trend at Summit, six times the global average trend, ranks in the 99th percentile of all globally observed temperature trends over the climatology period (Figure 2 inset). We note, however, that the polar regions, where recent warming has been greatest, are overrepresented in the $9 \%$ of the Earth's surface for which observed temperature trends are not available. Thus, the observed global mean temperature trend and the percentile rank of Summit are likely biased towards lower and higher values, respectively.

[12] Examining seasonal meteorological observations from the post-1987 continuous instrumental period provides insight on the relative contributions of seasonal changes on the evolution of mean annual NSAT (Figure S2). Since
1987, winter air temperatures exhibited a significant positive trend of $0.18 \pm 0.08^{\circ} \mathrm{C} / \mathrm{a}(\mathrm{r}=0.44, \mathrm{df}=22, \mathrm{p}<0.05)$, while both spring and summer air temperatures have increased at $0.08 \pm 0.06$ and $0.05 \pm 0.03^{\circ} \mathrm{C} / \mathrm{a}$, respectively. These latter trends, however, are not significant at the $\mathrm{p}<0.05$ level. Fall air temperatures have exhibited an insignificant $(\mathrm{p}>0.05)$ cooling trend over this period of $-0.03 \pm 0.05^{\circ} \mathrm{C} / \mathrm{a}$. Thus, changes in wintertime air temperature are the primary driver of changes in mean annual NSAT. While air temperatures appear to be increasing more quickly during winter and spring than summer, the implications of rising air temperatures during the melt season are more acute. For example, the record brief near-entire ice sheet surface melt on 11-12 July 2012 occurred as mean hourly NSATs at Summit exceeded $0^{\circ} \mathrm{C}$ for a combined $7 \mathrm{~h}$, reaching a maximum temperature of $0.6^{\circ} \mathrm{C}$.

[13] Increasing summer air temperatures have resulted in an upward migration of both the percolation facies and ablation area of the GrIS. The $0^{\circ} \mathrm{C} \mathrm{IE}$ migrated upward at a rate of $35 \mathrm{~m} / \mathrm{a}$ over the 1995-2012 period in West Greenland

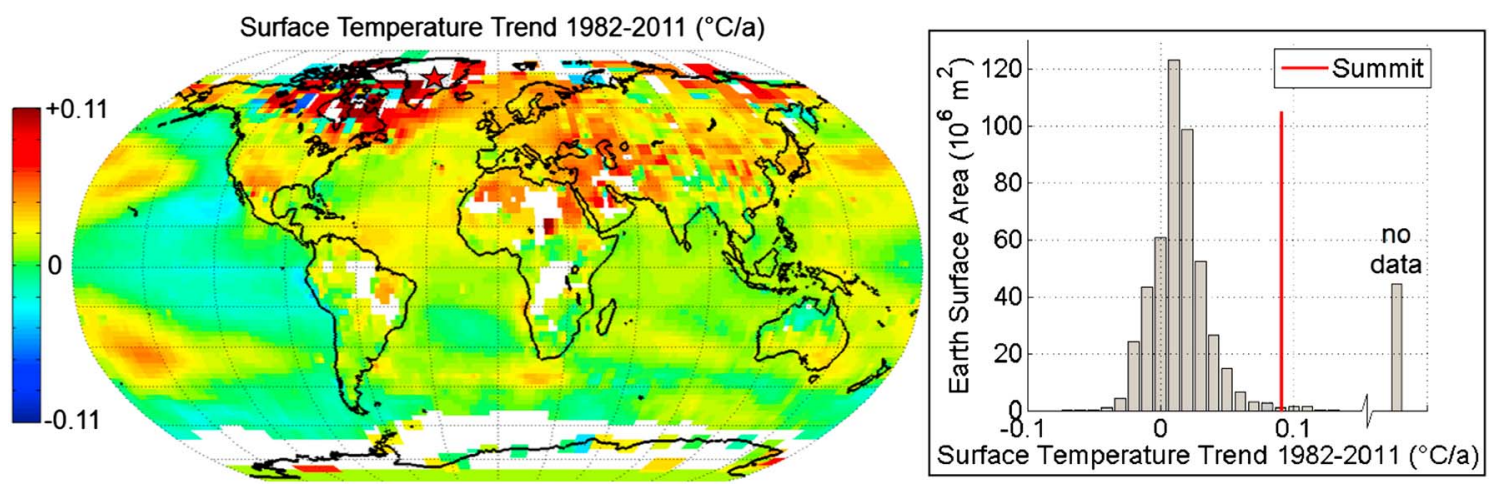

Figure 2. Spatial distribution of linear trends in surface temperature observed over the 1982-2011 period. White shading indicates no data. Data are plotted over $91 \%$ of the Earth's surface at $2^{\circ}$ resolution with a $250 \mathrm{~km}$ smoothing radius. The location of Summit, Greenland is indicated with a red star. Inset: Earth surface area versus surface temperature trend. The $0.09^{\circ} \mathrm{C} / \mathrm{a}$ trend observed at Summit places it in the 99th percentile of globally observed trends over the 1982-2011 period. 


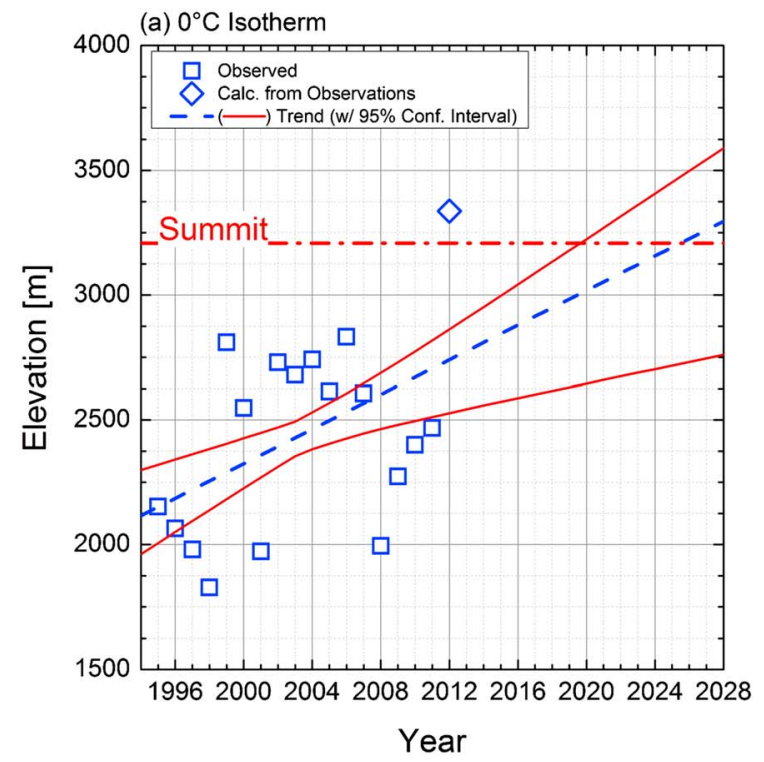

(b) Equilibrium Line Altitude

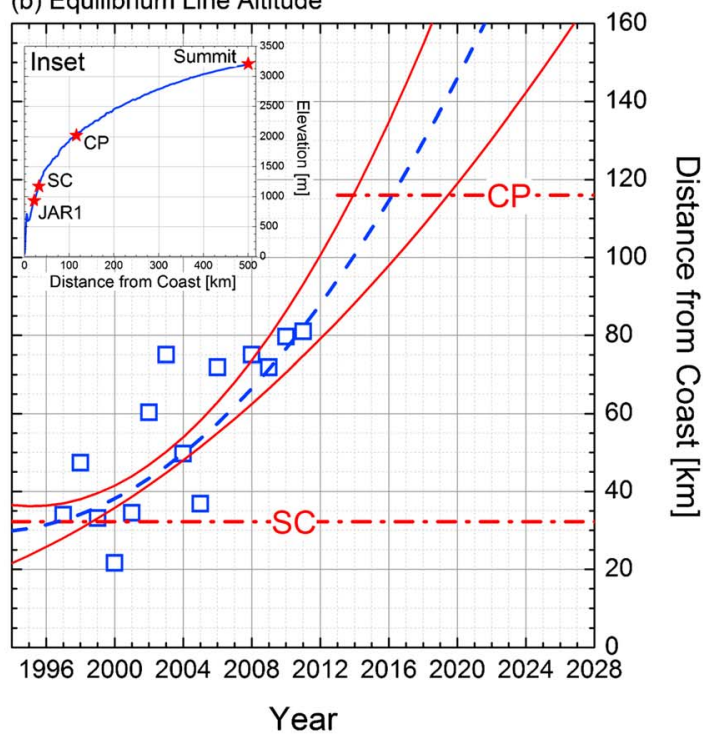

Figure 3. (a) Interpolated maximum elevation of $0^{\circ} \mathrm{C}$ isotherm from 1995 to 2012 and (b) mean equilibrium line altitude distance from coast from 1997 to 2011. Red dashed horizontal lines indicate the locations of Summit, Crawford Point (CP) and Swiss Camp (SC). Red lines are 95\% confidence intervals.

(Figure 3a). A bounded extrapolation of this trend now suggests, with $95 \%$ confidence intervals, that the dry snow facies of the GrIS will inevitably transition to percolation facies, as both the upper and lower confidence bounds have positive slopes. There is a $50 \%$ probability of the mean annual dry snow line migrating above Summit by 2025 , at which time Summit will experience routine melt on an annual basis. The surface mass balance observations similarly indicate that the ELA has migrated upwards at a rate of $44 \mathrm{~m} / \mathrm{a}$ over the 1997-2011 period in West Greenland, resulting in a more than doubling of the ablation zone width during this period (Figure 3b). Linear trends with elevation translate into exponential trends with distance when applied to the pronounced convex parabolic profile of the ablation zone.

\section{Mechanisms of Recent Warming}

[14] A persistent atmospheric circulation pattern, manifested as an anti-cyclonic high-pressure anomaly over the GrIS during the summer seasons from 2007-2012, has enhanced warm air advection along the west coast of Greenland and contributed to recent records in melt extent and runoff [e.g., Box et al., 2011, 2012a; Hanna et al., 2012; Tedesco et al., 2013]. While this pattern is consistent with the strongly negative North Atlantic Oscillation index during this period [Tedesco et al., 2013], a more specific metric, the Greenland Blocking Index, which emphasizes the $500 \mathrm{hPa}$ anomaly over the GrIS region, is more strongly correlated with GrIS surface mass balance over recent decades [Hanna et al., 2012].

[15] We note, however, that the long-term NSAT record suggests that the ongoing atmospheric warming at Summit began in the mid to late 1980s and thus is not solely a function of this specific circulation pattern. Gardner and Sharp [2007] attribute a shift to increased July air temperatures and decreased surface mass balance in the Canadian High Arctic after 1986 to a weakening and shifting of the circumpolar vortex. As a result of these changes in the circumpolar vortex, the Canadian High Arctic has become more thermally homogenous with lower latitudes, and hence warmer, since
1986 [Gardner and Sharp, 2007]. We interpret the nearcoincident shift in air temperatures at Summit, Greenland, as suggesting that the air temperature at Summit responds to changes in the polar vortex in a similar manner to air temperatures in the Canadian High Arctic. The intensity of this near surface warming since the late 1980s has been exacerbated by the dramatic reduction in Arctic Ocean sea ice cover [Screen and Simmonds, 2010a; Cavalieri and Parkinson, 2012]. The loss of summer sea ice cover not only permits a greater absorption of shortwave radiation during the summer, and hence a warming of the surface waters, but also increases the duration of ice free conditions into the fall/early winter, which enhances the longwave energy flux back to the atmosphere later in the year [Screen and Simmonds, 2010a]. The dominance of the winter warming trends throughout the Arctic has been attributed to this latter process, although the forcing is observed to decrease rapidly with atmospheric height, so its impact may be limited at Summit [Screen and Simmonds, 2010b]. Others have argued that warming aloft at $700-500 \mathrm{hPa}$ is driven by increased heat transport from afar, likely in response to increased sea surface temperature, although the statistical significance of this forcing is limited to the summer [Graversen et al., 2008; Screen et al., 2012].

\section{Implications for Greenland's Snow Zones}

[16] The melting observed at Summit in 2012 was an unprecedented event in the context of the observational record, and an extreme event in the context of the paleoclimate record [Clausen et al., 1988; Meese et al., 1994; Alley and Anandakrishnan, 1995]. We suggest, however, that the GrIS-wide melt event witnessed in 2012 is an anticipated consequence of the observed decadal scale atmospheric warming, rather than a singular extreme event. Our bounded extrapolation of an 18 year trend in dry snow line elevation, which assumes a constant rate of future change and subsequent response, demonstrates that Summit can no longer be reasonably expected to reside in the dry snow facies beyond 2025. This is in stark contrast to residing in the dry 
snow facies throughout the entire Holocene, except for rare, century-scale, extreme events [Alley and Anandakrishnan, 1995]. Regardless of the exact timing of this transition, there are important implications to a shrinking dry snow facies. First, an expansion of the percolation facies will contribute to a positive albedo feedback, whereby accelerated snow grain metamorphism lowers the surface reflectance and increases the absorption of solar radiation, further enhancing surface melt over a large area of the GrIS [Greuell, 2000; Box et al., 2012b]. Second, increased meltwater production over the lower reaches of the percolation facies can subsequently refreeze, substantially warming the near surface firn through the release of latent heat, significantly changing the surface temperature of the ice sheet with unknown effects on the supra- and en-glacial hydrology systems [e.g., Humphrey et al., 2012]. Lastly, this expansion will increase the area over which parameterizations of runoff and retention, which are highly sensitive to local snowpack properties and stratigraphy, must be implemented in prognostic models. The relative proportions of retention and runoff are currently a major uncertainty in projecting the future sea-level-rise contribution of the GrIS [Reijmer et al., 2012]. Recent field observations suggest meltwater runoff will be buffered from high elevations, as any melt will infiltrate and refreeze in the firn [Harper et al., 2012]. The ability for thick ice lenses produced by extreme melt events (i.e., 2012) to isolate this potential firn reservoir is unknown.

[17] The upward migration of the ELA and consequent nonlinear expansion in ablation area and contraction in accumulation area has clear surface mass balance implications. There are, however, also potential thermomechanical feedbacks that remain poorly understood. At present, summer acceleration in ice velocity, of up to $100 \%$ for several weeks, is widespread throughout land-terminating portions of the West Greenland ablation zone [Joughin et al., 2008]. This distinct summer acceleration results from increased basal sliding resulting from increased meltwater being delivered to an inefficient subglacial drainage system [Zwally et al., 2002; Joughin et al., 2008]. An expansion of the ablation zone will result in a larger region of the ice sheet experiencing acceleration in summer ice velocity, potentially increasing net ice discharge into the ablation zone. An increase in bare ice area will also increase the area over which crevasses are exposed at the surface. The net effect of increasing surface crevasse extent on ice sheet mass balance is poorly understood, as crevasses can alter both ice dynamics and surface mass balance via competing processes, such as enhancing deformational flow via cryo-hydrologic warming while suppressing basal sliding via attenuating meltwater pulses and enhancing meltwater production via decreasing surface albedo while increasing the retention fraction via increasing bulk ice porosity [Phillips et al., 2010; Colgan et al., 2011; McGrath et al., 2011].

\section{Summary Remarks}

[18] The $0.09 \pm 0.01^{\circ} \mathrm{C} / \mathrm{a}$ warming trend in mean annual NSAT observed at Summit, Greenland ranks in the 99th percentile of all globally observed warming trends over the 1982-2011 period. While the increase in NSAT appears to be dominated by winter season warming, summer season warming is significantly altering the snow zones of the GrIS. The $0^{\circ} \mathrm{CIE}$ and ELA are currently rising by $35 \mathrm{~m} / \mathrm{a}$ and
$44 \mathrm{~m} / \mathrm{a}$, respectively, in West Greenland. Due to the convex parabolic profile of the ice sheet, this is driving an exponential increase in the width of the ablation zone in West Greenland. While the surface melt that occurred at Summit in 2012 may be viewed as an extreme event in a paleoclimatic perspective, we suggest that it is an anticipated consequence of the ongoing climate change that is forcing the Arctic climate toward a warmer state. Extrapolation of observed trends now suggests, with $95 \%$ confidence intervals, that Summit will inevitably transition from dry snow facies to percolation facies. There is a $50 \%$ probability this transition to routine annual melt will occur by 2025 . This transition will signal the loss of the last major dry snow zone in the Arctic.

[19] Acknowledgments. NASA's Cryospheric Sciences Program (NNX08AT85G) funded this work with additional logistics support from the National Science Foundation Office of Polar Programs. We thank two anonymous reviewers for their thoughtful comments that improved the manuscript.

[20] The Editor thanks two anonymous reviewers for their assistance in evaluating this paper.

\section{References}

Alley, R. B., and S. Anandakrishnan (1995), Variations in melt-layer frequency in the GISP2 ice core: Implications for Holocene summer temperatures in central Greenland, Ann. Glaciol., 21, 64-70.

Benson, C. (1962, reprinted 1996), Stratigraphic studies in the snow and firn of the Greenland Ice Sheet. Snow, ice and permafrost research establishment, Rese. Rep., 70, $182 \mathrm{pp}$.

Box, J. E., et al. (2011), Greenland Ice Sheet (in Arctic Report Card 2011), available at www.arctic.noaa.gov/report11.

Box, J. E., et al. (2012a), Greenland Ice Sheet (in Arctic Report Card 2012), available at www.arctic.noaa.gov/reportcard.

Box, J. E., X. Fettweis, J. C. Stroeve, M. Tedesco, D. K. Hall, and K. Steffen (2012b), Greenland ice sheet albedo feedback: Thermodynamics and atmospheric drivers, Cryosphere, 6, 821-839. doi:10.5194/tc-6-821-2012.

Cavalieri, D. J., and C. L. Parkinson (2012), Arctic sea ice variability and trends, 1979-2010, Cryosphere, 6, 881-889. doi:10.5194/tc-6-881-2012.

Clausen, H. B., N. S. Gundestrup, S. J. Johnsen, R. Bindschadler, and J. Zwally (1988), Glaciological investigations in the Crete Area, Central Greenland: A search for a new deep-drilling site, Ann. Glaciol., 10, 10-15.

Colgan, W., K. Steffen, W. S. McLamb, W. Abdalati, H. Rajaram, R. Motyka, T. Phillips, and R. Anderson (2011), An increase in crevasse extent, West Greenland: Hydrologic implications, Geophys. Res. Lett., 38, L18502, doi:10.1029/2011GL04891.

Cuffey, K. M., and W. S. B. Paterson (2010), The Physics of Glaciers, fourth edition, p. 693, Butterworth-Heinemann, Oxford.

Gardner, A. S., and M. Sharp (2007), Influence of the Arctic circumpolar vortex on the mass balance of Canadian High Arctic glaciers, J. Climate, 30, 4586-4598. doi:10.1175/JCLI4268.1.

Graversen, R. G., T. Mauritsen, M. Tjernström, E. Källén, and G. Svensson (2008), Vertical structure of recent Arctic warming, Nature, 341, 53-57. doi:10.1038/nature06502.

Greuell, W. (2000), Melt-water accumulation on the surface of the Greenland Ice Sheet: Effect on albedo and mass balance, Geog. Ann., 82(4), 489-498.

Hanna, E., J. M. Jones, J. Cappelen, S. H. Mernild, L. Wood, K. Steffen, and P. Huybrechts (2012), The influence of North Atlantic atmospheric and oceanic forcing effects on 1900-2010 Greenland summer climate and ice melt/runoff, Int. J. Climatol., 33(4), 862-880, doi:10.1002/joc.3475.

Hansen, J., R. Ruedy, M. Sato, and K. Lo (2010), Global surface temperature change, Rev. Geophys., 48, RG4004, doi:10.1029/2010RG000345.

Harper, J., N. Humphrey, W. T. Pfeffer, J. Brown, and X. Fettweis (2012), Greenland ice-sheet contribution to sea-level rise buffered by meltwater storage in firn, Nature, 491, 240-243. doi:10.1038/nature11566.

Humphrey, N. F., J. T. Harper, and W. T. Pfeffer (2012), Thermal tracking of meltwater retention in Greenland's accumulation area, J. Geophys. Res., 117, F01010, doi:10.1029/200JF002083.

Joughin, I., S. B. Das, M. A. King, B. E. Smith, I. M. Howat, and T. Moon (2008), Seasonal speedup along the western flank of the Greenland Ice Sheet, Science, 320, 781-783. doi:10.1126/science.1153288.

McGrath, D., W. Colgan, K. Steffen, P. Lauffenburger, and J. Balog (2011), Assessing the summer water budget of a moulin basin in the Sermeq Avannarleq region, Greenland Ice Sheet, J. Glaciol., 57(205), 954-964.

Meese, D., A. J. Gow, P. Grootes, P. A. Mayewski, M. Ram, M. Stuiver, K C. Taylor, E. D. Waddington, and G. A. Zielinksi (1994), The 


\section{MCGRATH ET AL.: RECENT WARMING AT SUMMIT, GREENLAND}

accumulation record from the GISP2 core as an indicator of climate change throughout the Holocene, Science, 266, 1680-1682, doi:10.1126/science.266.5191.1680.

Nghiem, S. V., K. Steffen, R. Kwok, and W.-Y. Tsai (2001), Detection of snow melt regions on the Greenland ice sheet using diurnal backscatter change, J. Glaciol., 47(159), 539-547, doi:10.3189/172756501781831738.

Nghiem, S. V., D. K. Hall, T. L. Mote, M. Tedesco, M. R. Albert, K Keegan, C. A. Shuman, N. E. DiGirolamo, and G. Neumann (2012), The extreme melt across the Greenland Ice Sheet in 2012, Geophys. Res. Lett., 39, L20502, doi:10.2012/GL051598/2012GL053611.

Phillips, T., H. Rajaram, and K. Steffen (2010), Cryo-hydrologic warming: A potential mechanism for rapid thermal response of ice sheets, Geophys. Res. Lett., 37, L20503, doi:10.2012/GL051598/2010GL044397.

Reijmer, C. H., M. R. van den Broeke, X. Fettweis, J. Ettema, and L. B. Stap (2012), Refreezing on the Greenland ice sheet: A comparison of parameterizations, Cryosphere, 6, 743-762, doi:10.5194/tc-6-743-2012.

Rienecker, M. M. et al. (2011), MERRA - NASA's Modern-Era Retrospective Analysis for Research and Applications, J. Climate, 24, 3624-3648, doi:10.1175/JCLI-D-11-00015.1.

Reynolds, R. W., N. A. Rayner, T. M. Smith, D. C. Stokes, and W. Wang (2002), An improved in situ and satellite SST analysis for climate, $J$. Climate, 15, 1609-1625.

Rignot, E., J. E. Box, E. Burgess, and E. Hanna (2008), Mass balance of the Greenland Ice Sheet from 1958 to 2007, Geophys. Res. Lett., 35, L20502, doi:10.1029/2008GL035417.

Rignot, E., I. Velicogna, M. R. van den Broeke, A. Monaghan, and J. T. M Lenaerts (2011), Acceleration of the contribution of the Greenland and Antarctic ice sheets to sea level rise, Geophys. Res. Lett., 38, L05503, doi:10.1029/2011GL046583.

Scambos, T. A., and T. Haran (2002), An image-enhanced DEM of the Greenland ice sheet, Ann. Glaciol., 34, 291-298.
Screen, J. A., and I. Simmonds (2010a), Increasing fall-winter energy loss from the Arctic Ocean and its role in Arctic temperature amplification, Geophys. Res. Lett., 37, L15707, doi:10.1029/2010GL044136.

Screen, J. A., and I. Simmonds (2010b), The central role of diminishing sea ice in recent Arctic temperature amplification, Nature, 464, 1334-1337, doi:10.1038/nature09051.

Screen, J. A., C. Deser, and I. Simmonds (2012), Local and remote controls on observed Arctic warming, Geophys. Res. Lett., 39, L10709, doi:10.1029/2012GL051598.

Steffen, K., W. Abdalati, and J. Stroeve (1993), Climate sensitivity studies of the Greenland ice sheet using satellite AVHRR, SMMR, SSM/I and in situ data, Meteor. and Atmos. Phys., 51(3-4), 239-258.

Steffen, K., and J. Box (2001), Surface climatology of the Greenland ice sheet: Greenland Climate Network 1995-1999, J. Geophys. Res., 106(D24), 33,951-33,964.

Tedesco, M., X. Fettweis, M. R. van den Broeke, R. S. W. van de Wal, C. J. P. P. Smeets, W. J. van de Berg, M. C. Serreze, and J. E. Box (2011), The role of albedo and accumulation in the 2010 melting record in Greenland, Envir. Res. Lett., 6, doi:10.1088/1748-9326/6/1/014005.

Tedesco, M., X. Fettweis, T. Mote, J. Wahr, P. Alexander, J. Box, and B. Wouters (2013), Evidence and analysis of 2012 Greenland records from spaceborne observations, a regional climate model and reanalysis data, The Cryosphere, 7, 615-630, doi:10.5194/tc-7-615-2013.

van den Broeke, M., J. Bamber, J. Ettema, E. Rignot, E. Schrama, W. J. van de Berg, E. Van Meijgaard, I. Velicogna, and B. Wouters (2009), Partitioning recent Greenland mass loss, Science, 326, doi:10.1126/science.1178176.

Velicogna, I., and J. Wahr (2006), Acceleration of Greenland ice mass loss in spring 2004, Nature, 443(21), doi:10.1038/nature05168.

Zwally, H. J., W. Abdalati, T. Herring, K. Larson, J. Saba, and K. Steffen (2002), Surface melt-induced acceleration of Greenland Ice-Sheet flow, Science, 297, 218-222, doi:10.1126/science.1072708. 